\title{
Managing Successful Pregnancies in Patients with Chronic Intestinal Failure on Home Parenteral Nutrition: Experience from a UK National Intestinal Failure Unit
}

DOI:

10.15403/jgld.2014.1121.264.ukn

\section{Document Version \\ Accepted author manuscript}

Link to publication record in Manchester Research Explorer

Citation for published version (APA):

Bond, A., Vasant, D., Gashau, W., Abraham, A., Teubner, A., Farrer, K., Leahy, G., \& Lal, S. (2017). Managing Successful Pregnancies in Patients with Chronic Intestinal Failure on Home Parenteral Nutrition: Experience from a UK National Intestinal Failure Unit. Journal of Gastrointestinal and Liver Diseases, 26(4), 375-379. https://doi.org/10.15403/jgld.2014.1121.264.ukn

\section{Published in:}

Journal of Gastrointestinal and Liver Diseases

\section{Citing this paper}

Please note that where the full-text provided on Manchester Research Explorer is the Author Accepted Manuscript or Proof version this may differ from the final Published version. If citing, it is advised that you check and use the publisher's definitive version.

\section{General rights}

Copyright and moral rights for the publications made accessible in the Research Explorer are retained by the authors and/or other copyright owners and it is a condition of accessing publications that users recognise and abide by the legal requirements associated with these rights.

\section{Takedown policy}

If you believe that this document breaches copyright please refer to the University of Manchester's Takedown Procedures [http://man.ac.uk/04Y6Bo] or contact uml.scholarlycommunications@manchester.ac.uk providing relevant details, so we can investigate your claim.

\section{OPEN ACCESS}




\title{
Managing Successful Pregnancies in Patients with Chronic Intestinal Failure on Home Parenteral Nutrition: Experience from a UK National Intestinal Failure Unit
}

\author{
Ashley Bond ${ }^{1}$, Dipesh H. Vasant ${ }^{1,2}$, Wadiamu Gashau ${ }^{1}$, Arun Abraham ${ }^{1}$, Antje Teubner ${ }^{1}$, Kristine Farrer ${ }^{1}$, Gavin Leahy ${ }^{1}$,
} Simon Lal ${ }^{1,2}$

1) Intestinal Failure, Salford

Royal Foundation NHS Trust, Salford, United Kingdom; 2) Manchester Academic Health Sciences Centre, University of Manchester, Manchester, United Kingdom

Address for correspondence: Prof. Simon Lal

Intestinal Failure Unit Salford Royal Foundation Trust, Salford United Kingdom Simon.Lal@srft.nhs.uk
Received: 13.07.2017

Accepted: 22.09.2017

\section{ABSTRACT}

Background \& Aim: There are minimal reports of pregnancy in the chronic intestinal failure (CIF)/ home parenteral nutrition (HPN) population, with some concern relating to the risk associated with such pregnancies. The aim of this retrospective observational study was to evaluate pregnancy experience and outcomes in patients with CIF requiring HPN in a national UK CIF referral centre.

Method. All known pregnancies in patients treated with HPN for CIF between 1982 and 2016 were identified retrospectively from a prospectively maintained database. Maternal and foetal outcomes were collated, along with PN requirements before and during pregnancy.

Results. There were 5 pregnancies in 5 mothers in our cohort consisting of over 700 patients, males and females. The median age at conception was 28 years (range $24-33$ years). The median duration on HPN prior to pregnancy was 26 months (range 4-85 months). One patient had Crohn's disease, another had pan-enteric dysmotility and the other three patients had ischaemic complications leading to short bowel syndrome (SBS). All mothers were intensively monitored in an obstetric clinic and a dedicated CIF multi-disciplinary clinic throughout pregnancy. There were $2 / 5$ preterm deliveries. One of the preterm deliveries was associated with spontaneous labour and the other had a planned induction as a result of maternal clinical need. Neonatal complications were seen in both prenates. There were no recorded maternal catheter related line infections during the 5 pregnancies.

Conclusion. Successful pregnancy whilst receiving HPN is feasible but requires close, intensive monitoring and dedicated optimisation of PN in order to minimise maternal and foetal complications. All women of child-bearing age on HPN should be counselled about pregnancy.

Key words: Pregnancy - home parenteral nutrition - intestinal failure.

Abbreviations: ALP: alkaline phosphatase; ALT: alanine transaminase; CIF: chronic intestinal failure ; HPN: home parenteral nutrition; IBD: inflammatory bowel disease; IFALD: Intestinal Failure associated liver disease; LFT: liver function test; NIEHS: National Institute of Environmental Health Sciences; PN: parenteral nutrition; RDA: Recommended daily allowance; SBS: short bowel syndrome.

\section{INTRODUCTION}

Chronic (Type III) intestinal failure (CIF) leading to the need for home parenteral nutrition (HPN) usually occurs as a result of short bowel syndrome (SBS), inflammatory bowel disease (IBD), gastrointestinal motility disorders, enteropathies and intestinal fistulas [1]. Chronic intestinal failure is associated with well documented clinical risks which include Intestinal
Failure associated liver disease (IFALD), chronic kidney disease, biliary stones, osteoporosis and recurrent venous access complications, including thrombosis and infections [2, 3]. However, with careful multidisciplinary management, these complications can be minimised and patients can maintain a good quality of life [2-4]. As a result of this, women of childbearing age established on HPN may be increasingly more likely to consider pregnancy. However, most of the published reports of PN use in pregnancy relate to its use in non-IF cases including anorexia nervosa, hyperemesis and pancreatitis associated with pregnancy [5-8]. There are very few published reports and studies on pregnancy outcomes in patients with CIF both in patients receiving long-term parenteral nutrition (PN) [9-12] and those post-intestinal transplantation $[13,14]$. 
From a nutritional perspective, there are a number of pregnancy-specific considerations in patients with CIF, both maternal and foetal, including an increase in maternal nutritional requirement, early miscarriage, late foetal loss as well as micronutrient deficiencies e.g. vitamins A, B9, D, $\mathrm{K}$, iron and/or zinc may have significant consequences for foetal development $[10,15]$ Here, we report the management and outcomes of five pregnancy cases in patients with CIF established on HPN in our intestinal failure unit.

\section{METHODS}

In a retrospective observational study of all pregnant patients on HPN from a national UK referral intestinal failure centre, all known pregnant patients treated with HPN for CIF between 1982 and 2016 were identified. Inclusion criteria were: CIF patients between these dates at our centre and occurrence of a reported pregnancy over this period. The patients benefited from multidisciplinary care involving gastroenterologists, nurses, dietitians, pharmacists, obstetricians and psychologists. Data on demographics, comorbidities, nutritional support characteristics, foetal progress, newborn weights, maternal and newborn complications, HPN complications (such as catheter sepsis, thrombosis and IFALD) were collected. Energy and nitrogen requirements for each individual were assessed using the Schofield equation and Elia normogram, respectively, and due consideration was given to the recommendations on energy requirements by Butte et al. 2004 [16-18]. Micronutrient alterations were guided by recommended daily allowances (RDA) already precedent in obstetric care, adjusted according to biochemical and haematological indices checked regularly throughout gestation.

\section{RESULTS}

Overall, five pregnancies and five successful births were identified in five mothers under our care between 1982 and 2016. There were no maternal or foetal deaths observed. There were no specific HPN related complications recorded in any of the mothers; though one mother developed transiently abnormal liver function tests, this may have related to her underlying pregnancy rather than IFALD (see below).

\section{Patient characteristics and pregnancy outcomes}

The median duration on HPN prior to pregnancy was 26 months (range 4-85 months). One mother had Crohn's disease leading to CIF, another had pan-enteric dysmotility and the other three patients had ischaemic complications leading to SBS (Table I). The median age at conception was 28 years (range $24-33$ years). Median maternal weight gain was $5 \mathrm{~kg}$ (range $1-5.5 \mathrm{~kg}$ ). Three out of five pregnancies went to term. One of the preterm deliveries was associated with spontaneous labour and the other had a planned induction. One baby was born via elective Caeserian section as a result of maternal clinical need, with the other four being born via normal vaginal delivery. Neonatal complications were seen in both prenates (born at 30 and 34 weeks gestation) and were a direct consequence of preterm delivery, namely respiratory distress leading to the need for mechanical ventilation and sepsis. Mean foetal birth weight was $3 \mathrm{~kg}$ (range $1.3-3.3 \mathrm{~kg}$ ).

Table I. Patient demographic, maternal and foetal clinical parameters

\begin{tabular}{|c|c|c|c|c|c|c|c|c|}
\hline Patient & $\begin{array}{l}\text { Maternal } \\
\text { age at } \\
\text { conception }\end{array}$ & $\begin{array}{c}\text { Cause of } \\
\text { intestinal } \\
\text { failure }\end{array}$ & $\begin{array}{c}\text { Pre- } \\
\text { conception } \\
\text { PN } \\
\text { duration } \\
\text { (months) }\end{array}$ & $\begin{array}{l}\text { Gestation } \\
\text { at birth } \\
\text { (weeks) }\end{array}$ & $\begin{array}{l}\text { Mode of } \\
\text { delivery }\end{array}$ & $\begin{array}{c}\text { Maternal } \\
\text { complications }\end{array}$ & $\begin{array}{c}\text { Foetal } \\
\text { complications }\end{array}$ & $\begin{array}{l}\text { Foetal birth } \\
\text { weight }(\mathrm{kg})\end{array}$ \\
\hline 1 & 32 & $\begin{array}{l}\text { Extensive SB } \\
\text { Crohns }\end{array}$ & 4 & 37 & Vaginal & Nil & Nil & 2.6 \\
\hline 2 & 28 & $\begin{array}{l}\text { Short bowel } \\
\text { syndrome } \\
\text { (SMA } \\
\text { thrombus) }\end{array}$ & 26 & 30 & C-section & Nil & $\begin{array}{l}\text { Pre-term } \\
\text { labour, } \\
\text { cleft palate, } \\
\text { respiratory } \\
\text { distress and } \\
\text { mechanical } \\
\text { ventilation }\end{array}$ & 1.3 \\
\hline 3 & 33 & $\begin{array}{l}\text { Short Bowel } \\
\text { Syndrome } \\
\text { (mesenteric } \\
\text { ischaemia) }\end{array}$ & 85 & 37 & C-section & $\begin{array}{c}\text { Weight } \\
\text { loss late in } \\
\text { pregnancy }\end{array}$ & Nil & 2.1 \\
\hline 4 & 26 & $\begin{array}{c}\text { SMA } \\
\text { thrombosis }\end{array}$ & 80 & 36 & Vaginal & $\begin{array}{l}\text { Abnormal } \\
\text { liver function, } \\
\text { gestational } \\
\text { diabetes, } \\
\text { weight loss }\end{array}$ & Nil & 3.1 \\
\hline 5 & 25 & $\begin{array}{l}\text { pan enteric } \\
\text { dysmotility }\end{array}$ & 17 & $\begin{array}{c}34 \\
\text { induction }\end{array}$ & Vaginal & nil & $\begin{array}{l}\text { foetal sepsis } \\
\text { needing ICU }\end{array}$ & 3 \\
\hline
\end{tabular}

PN: parenteral nutrition; SB: small bowel; SMA superior mesenteric artery 
The baseline characteristics of the patients, including the cause for intestinal failure and pregnancy outcomes are summarised in Table I.

Nutritional monitoring approach and individual management

In pregnant patients on HPN at our centre, the frequency of blood monitoring (including full blood count, liver function and electrolytes) was increased to monthly with a regular measurement of iron indices, zinc, copper selenium and folate. Vitamins A and $\mathrm{E}$ and $\mathrm{B} 12$ were monitored at presentation with pregnancy diagnosis and at 3 monthly intervals thereafter. Micronutrients, along with other biochemical parameters were monitored and adjusted following frequent review in an outpatient setting. Parenteral nutrition requirements at conception and maximum requirements during pregnancy are outlined in Table II.

\section{Patient 1 (Year of pregnancy, 1982)}

This patient's pregnancy at the time was believed to be the first ever reported pregnancy in a patient with CIF on HPN in the UK according to documentation in the medical records. Pregnancy was not planned in this case; the patient was reviewed routinely in the clinic and noted to have gained a significant amount of weight. Examination demonstrated findings in line with pregnancy. Subsequent ultrasound scanning confirmed a pregnancy of approximately 25 weeks gestation. At the point of conception the patient was receiving Intralipid $20 \%$ once per week, containing 2000kcal. This was in conjunction with $\mathrm{x} 5$ glucose bags containing $1000 \mathrm{kcal}$ per week. Fat-soluble vitamins were increased during the pregnancy and energy requirements met with increased PN calories. At 37 weeks, spontaneous labour resulted in delivery.

Nitrogen content for this case was not recorded because of archived records of over 30 years.

\section{Patient 2 (Year of pregnancy, 1994)}

Pregnancy was not planned in this case and was confirmed at 9 weeks gestation. Parenteral nutrition regimen at this point was 3 litres, $1400 \mathrm{kcal}$ and $9 \mathrm{~g}$ nitrogen 7 -days per week, administered in the combination of 5 lipid-free and 2 lipid bags (Intralipid). In the second trimester, calories were increased in line with requirements, to a maximum of $1900 \mathrm{kcal}$ per day. Premature labour ensued at 30 weeks gestation.

\section{Patient 3 (Year of pregnancy, 2003)}

At the point of conception the patient was receiving 3 litres, $1400 \mathrm{kcal}$ and $9 \mathrm{~g}$ nitrogen. Zinc and folate content were increased once pregnancy confirmed. In the second trimester calories were increased to $1500 \mathrm{kcal}$ and again at 30 weeks to $1600 \mathrm{kcal}$. The nitrogen content of the bag remained at 9 $\mathrm{g}$ nitrogen throughout the pregnancy. The patient was also receiving $10 \% 100 \mathrm{ml}$ of Vitilipid N Adult $10 \mathrm{ml}$ to provide fat soluble vitamins.

\section{Patient 4 (Year of pregnancy, 2004)}

At the time of conception, the patient was established on a PN regimen over 7 nights supplying $1800 \mathrm{kcal}$ per day with $9 \mathrm{~g}$ of nitrogen. There was no change to the PN regimen at conception, but zinc and folate content were increased. At 16 weeks gestation, calories were increased to 2000kcal per day with $9 \mathrm{~g}$ of nitrogen. At week 24, maternal weight remained stable at $55 \mathrm{~kg}$, BMI $19.7 \mathrm{~kg} / \mathrm{m}^{2}$. At this point, calories were increased to $2400 \mathrm{kcal} /$ day with $11 \mathrm{~g}$ nitrogen. The patient developed signs and symptoms of early gestational diabetes, along with abnormal liver functions tests (LFTs) peaking at ALP 550 and ALT of 215 but no jaundice. At week 31, calories were reduced back down to $2200 \mathrm{kcal}$ per day. By controlling the calorie content of the PN regimen, the need for insulin was obviated. At 36 weeks gestation, the patient went into spontaneous labour and delivered an infant with a birth weight of $3.1 \mathrm{~kg}$; the patient's LFTs subsequently improved.

\section{Patient 5 (Year of pregnancy, 2013)}

Conception of the child was planned in conjunction with the Intestinal Failure Unit team and, therefore, folic acid contents in the PN regime were increased preconception. At the time of conception, the patient was receiving 2.5 litres, $1800 \mathrm{kcal}$ and $9 \mathrm{~g}$ nitrogen per bag. She was receiving PN 7 nights per week as a 5 nights lipid-free with 2 nights lipid containing regimen. During the second trimester, the energy content was increased to $2000 \mathrm{kcal}$ per day, with a $200 \mathrm{kcal}$ increase every 4 weeks thereafter. Elective induction took place at 34 weeks as per obstetrics advice, at which point the patient was receiving $2400 \mathrm{kcal}$ per bag and 13g of nitrogen.

\section{DISCUSSION}

This study demonstrates that when pregnancy occurs in patients with CIF, close monitoring by a multidisciplinary team and customised nutritional support can lead to good outcomes for both mother and baby. The duration of data collection spanned over three decades and includes the first known pregnancy of its kind in the UK from 1982.

Table II. Home parental nutrition (HPN) requirements and nutritional assessments during pregnancy.

\begin{tabular}{lcccccc}
\hline Patient & $\begin{array}{c}\text { PN volume at } \\
\text { conception }\end{array}$ & $\begin{array}{c}\text { Lipid (F)/Glucose } \\
(\mathrm{G}) \text { ratio }\end{array}$ & $\begin{array}{c}\text { Total Energy per } \\
\text { day at conception } \\
\text { (kcal) }\end{array}$ & $\begin{array}{c}\text { Max energy during } \\
\text { pregnancy (kcal) }\end{array}$ & $\begin{array}{c}\text { Nitrogen at } \\
\text { conception (g) }\end{array}$ & $\begin{array}{c}\text { Max nitrogen at } \\
\text { conception (g) }\end{array}$ \\
\hline 1 & $\begin{array}{c}1000 \mathrm{ml} \times 5 \text { and } \\
2000 \mathrm{ml} \text { x1 }\end{array}$ & $1 \mathrm{~F} / 5 \mathrm{G}$ & $1000 \times 5$ and 2000x1 & $1500 \times 5$ and 2000x1 & Not recorded & Not recorded \\
2 & $3000 \mathrm{ml}$ & $2 \mathrm{~F} / 5 \mathrm{G}$ & 1400 & 2300 & 9 & 11 \\
3 & $3000 \mathrm{ml}$ & $1 \mathrm{~F} / 6 \mathrm{G}$ & 1400 & 2200 & 9 & 11 \\
4 & $3000 \mathrm{ml}$ & $2 \mathrm{~F} / 5 \mathrm{G}$ & 1800 & 2400 & 9 & 11 \\
5 & $2500 \mathrm{ml}$ & $2 \mathrm{~F} / 5 \mathrm{G}$ & 1800 & 2400 & 9 & 13 \\
\hline
\end{tabular}


Our study confirms that pregnancy is possible in CIF, even after years of HPN. Two of the five pregnancies in the present study were associated with a maternal complication, with a $40 \%$ foetal complication rate, rates lower than other such studies have reported [9-11]. In our cohort, gestational weights were within the 20th to 75th centiles and there were two pre-term deliveries, one of which was a planned induction. Suggestion of increase in pre-term deliveries has been reported in HPN patients. During the period of data collection, there were significant changes in the approach to managing patients requiring HPN including the lipid profile of the $\mathrm{PN}$ and the relevance of these changes in terms of pregnancy outcomes is unclear. Patients treated before 2000 were receiving first generation lipid (Intralipid), whereas post 2000, patients were receiving second generation lipids. There is however no convincing literature to-date supporting that lipid composition of $\mathrm{PN}$ is causally linked to the development of pre-term labour. Indeed, all five of our patients received a proportion of their calorific requirement via a lipid source. Our practice in all CIF patients is to limit the amount of lipid given, wherever possible, to less than $20 \%$ of weekly PN administered, in order to minimise the risk of developing IFALD. In pregnancy, data from murine studies support our approach, whereby placental fatty infiltration was observed following PN consisting of 50\% lipid composition $[21,22]$ but when lipids accounted for only $20 \%$ of calorific intake, placental fatty infiltration was not seen. Of note, placentas from two separate pregnancies in our cohort were histologically normal post-partum with no evidence of lipid deposition.

Clearly counselling of patients of child bearing age receiving HPN should be specifically counselled regarding pregnancy. Firstly, that pregnancy is possible and secondly that pregnancy is best planned to allow for optimisation. Contraception advice may form part of this process. Such planning will allow the optimisation of HPN constituents such as folate and zinc, but will also allow for early obstetric monitoring and assessment. Obstetricians specialising in medical disorders in pregnancy are best placed to co-manage such patients. Energy requirements will alter during the pregnancy so regular assessment must take place to ensure these are being met. These will also need to be altered in the post-partum phase. Historically, there is $15 \mathrm{mg}$ of folic acid once a week in each patients' TPN. When a patient becomes pregnant this would be increased to $15 \mathrm{mg}$ 3 times per week for the duration of the pregnancy. In 2016, additional folic acid was taken out of patients' TPN, as they get $0.4 \mathrm{mg}$ daily (the RDA for adults is $0.2 \mathrm{mg}$ ) through the addition of solivito $\mathrm{N}$ to every lipid or glucose bag. We have historically started the increased doses of folic acid for those patients who we knew were trying to become pregnant.

Billiauws et al. [10] conducted a study across four HPN centres in France, that included 15 patients (a total of 21 pregnancies). More than $60 \%$ of the patients experienced complications during their pregnancy due to the pregnancy, to the underlying disease or due to HPN. The main complications were the occurrence of catheter occlusion and catheter-related infections [10]. Our centre reports one of the lowest sustained catheter related infection rates worldwide [2], and notably, there were no catheter related complications in our series, highlighting the importance of maintaining excellent catheter care particularly in this physiologically vulnerable group of HPN patients with known pregnancy. The most potentially serious maternal complication observed in our cohort was abnormal liver function; the exact aetiology of which remained unclear and may have been related to PN or pregnancy itself. However, it is noteworthy that the patient's liver function tests improved after pregnancy.

Foetal complications occurred in $2 / 5$ pregnancies. Specifically these were cleft palate and respiratory compromise requiring mechanical ventilation. Folate and other $\mathrm{B}$ vitamin deficiencies have been demonstrated to be associated with cleft palate. A population-based study conducted in Norway, which has one of the highest rates of facial clefts in Europe, estimated that 22 percent of isolated cleft palate cases in Norway could be averted if all pregnant women took $0.4 \mathrm{mg}$ of folic acid per day. This was supported by research at the National Institute of Environmental Health Sciences (NIEHS) in the USA, part of the National Institutes of Health, who found that $0.4 \mathrm{mg}$ a day of folic acid reduced a babies risk of isolated cleft lip by one third [19]. The occurrence of cleft palate in our cohort was in an unplanned pregnancy and therefore it is plausible that increased folic acid prior to conception could have reduced the risk. The respiratory distress in this case was likely related to the early gestational age at birth. Premature birth is again a commonly reported foetal complication for mothers receiving HPN [10]. Studies conducted in patients who have undergone bariatric surgery have also highlighted the significant impact of hypovitaminosis on foetal morbidity, including neural tube defects, eye anomalies, and intracranial haemorrhage. Moreover, zinc deficiency has generally been associated with foetal malformations as well as growth retardation, prematurity, and perinatal death. Hence, micronutrient monitoring and adequate substitution of vitamin A, vitamin $\mathrm{D}$, vitamin $\mathrm{K}$, zinc, and folic acid in particular are recommended in all patients at nutritional risk [11, 20-23].

The total number of pregnancies in our cohort is low, with three of the five being post 2000. This is likely due to medical advancements and an earlier reluctance for HPN patients to become pregnant. In fact, we report what is thought to be the first HPN pregnancy in Europe. As the use of HPN increase and our understanding of this matter improves, pregnancy rate in HPN patients is likely to increase.

\section{CONCLUSION}

This retrospective observational study is the largest series of pregnancy outcomes in PN dependent CIF patients in the UK. Our experience suggests that multidisciplinary management, careful planning, monitoring and supplementation of micronutrients and calorie intake can minimise complications and result in successful maternal and foetal outcomes. All women of child-bearing age on HPN should be counselled about pregnancy. Ideally, pregnancy should be planned to allow appropriate monitoring. With appropriate support, pregnancy and delivery can occur uneventfully with minor adjustments required in established HPN regimes to ensure adequate foetal growth.

Conflicts of interest: The authors have no conflicts of interest to declare. 
Authors' contribution: A.B. collected data and information, wrote and edited the manuscript. D.V. wrote and edited the manuscript. G.W. assisted with data collection. A.A., A.T., K.F. and G.L. reviewed and edited the manuscript prior to submission. S.L. devised the study, advised throughout, reviewed and edited the manuscript prior to submission.

\section{REFERENCES}

1. Pironi L, Arends J, Bozzetti F, et al. ESPEN guidelines on chronic intestinal failure in adults. Clin Nutr 2016;35:247-307. doi:10.1016/j. clnu.2016.01.020

2. Dibb M, Soop M, Teubner A, et al. Survival and nutritional dependence on home parenteral nutrition: Three decades of experience from a single referral centre. Clin Nutr 2016;16:S0261-S5614. doi:10.1016/j. clnu.2016.01.028

3. Dibb M, Teubner A, Theis V, Shaffer J, Lal S. Review article: The management of long-term parenteral nutrition. Aliment Pharmacol Ther 2013;37:587-603. doi:10.1111/apt.12209

4. Winkler MF, Smith CE. Clinical, social, and economic impacts of home parenteral nutrition dependence in short bowel syndrome. JPEN J Parenter Enteral Nutr 2014;38(1 Suppl):32S-37S. doi:10.1177/0148607113517717

5. Russo-Stieglitz KE, Levine AB, Wagner BA, Armenti VT. A. Pregnancy outcome in patients requiring parenteral nutrition. J Matern Fetal Med 1999;8:164-167.

6. Levine M, Esser D. Total parenteral nutrition for the treatment of severe hyperemesis gravidum: maternal nutritional effects and fetal outcome. Obstet Gynecol 1988;72:102-107.

7. Van Stuijvenberg ME, Schabort I, Labadarios D, Nel JT. The nutritional status and treatment of patients with hyperemesis gravidarum. Am J Obstet Gynecol 1995;1585-1591. doi:10.1016/0002-9378(95)90501-4

8. Lakoff KM, Feldman JD. Anorexia nervosa associated with pregnancy. Obstet Gynecol 1972;39:699-701.

9. Theilla, M, Ławiński M, Cohen J, et al. Safety of home parenteral nutrition during pregnancy. Clin Nutr 2017;36:288-292. doi:10.1016/j. clnu.2015.12.001

10. Billiauws L, Armengol Debeir L, Poullenot F, et al. Pregnancy is possible on long-term home parenteral nutrition in patients with chronic intestinal failure: Results of a long term retrospective observational study. Clin Nutr 2017;36:1165-1169. doi:10.1016/j.clnu.2016.08.007

11. Buchholz BM, Rüland A, Kiefer N, et al. Conception, Pregnancy, and Lactation Despite Chronic Intestinal Failure Requiring Home Parenteral Nutrition. Nutr Clin Pract 2015;30:807-814. doi:10.1177/0884533615574003

12. Borbolla Foster A, Dixon S, Tyrrell-Price J, Trinder J. Pregnancy and lactation during long-term total parenteral nutrition: A case report and literature review. Obstet Med 2016;9:181-184. doi:10.1177/1753495X16670761

13. Blackwell V, Holdaway L, Hogan J, et al. Multidisciplinary care ensures successful pregnancy following intestinal transplantation: a case report. BJOG 2017;124:825-828. doi:10.1111/1471-0528.14420

14. Lauro A, Matsumoto CS, Marino IR, Berghella V. A review on pregnancy after intestinal transplantation. J Matern Fetal Neonatal Med 2017;30:205-212. doi:10.3109/14767058.2016.1168801

15. Godfrey KM, Barker DJ. Fetal nutrition and adult disease. Am J Clin Nutr 2000;71(5 Suppl):1344S-1352S.

16. Butte NF, Wong WW, Treuth MS, Ellis KJ, O’Brian Smith E. Energy requirements during pregnancy based on total energy expenditure and energy deposition. Am J Clin Nutr 2004;79:1078-1087.

17. Elia M. Artifiicial nutritional support. Med Int 1990;82:3392-3396.

18. Schofield WN. Predicting basal metabolic rate, new standards and review of previous work. Hum Nutr Clin Nutr 1985;39:5-41.

19. Wilcox AJ, Lie RT, Solvoll K, et al. Folic acid supplements and risk of facial clefts: national population based case-control study. BMJ 2007;334:464. doi:10.1136/bmj.39079.618287.0B

20. Institute of Medicine. Dietary Reference Intakes for Thiamin, Riboflavin, Niacin, Vitamin B6, Folate, Pantothenic Acid, Biotin, and Choline. Washington, DC: The National Academies Press, 1998. doi:10.17226/6015

21. Jameson S. Zinc status in pregnancy: the effect of zinc therapy on perinatal mortality, prematurity, and placental ablation. Ann N Y Acad Sci 1993;678:178-192. doi:10.1111/j.1749-6632.1993.tb26121.x

22. Guelinckx I, Devlieger R, Vansant G. Reproductive outcome after bariatric surgery: a critical review. Hum Reprod Update 2009;15:189201. doi:10.1093/humupd/dmn057

23. Saltzman E, Karl JP. Nutrient deficiencies after gastric bypass surgery. Annu Rev Nutr 2013;33:183-203. doi:10.1146/annurevnutr-071812-161225 